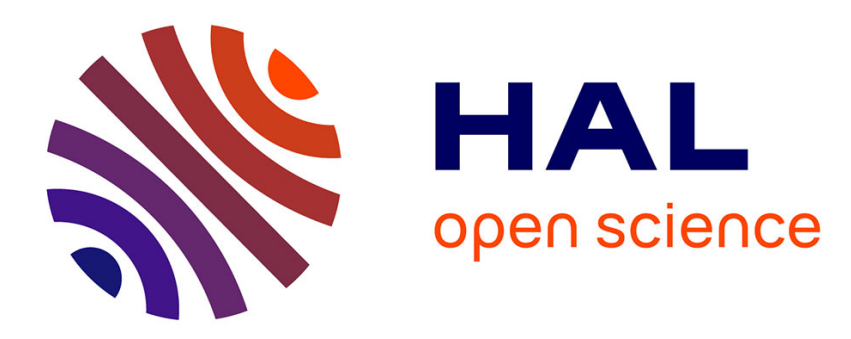

\title{
Gallstone disease, towards a better understanding and clinical practice
}

Chantal Housset

\section{To cite this version:}

Chantal Housset. Gallstone disease, towards a better understanding and clinical practice. Current Opinion in Gastroenterology, 2018, 34 (2), pp.57-58. 10.1097/MOG.0000000000000425 . hal02172115

\section{HAL Id: hal-02172115 \\ https://hal.sorbonne-universite.fr/hal-02172115}

Submitted on 3 Jul 2019

HAL is a multi-disciplinary open access archive for the deposit and dissemination of scientific research documents, whether they are published or not. The documents may come from teaching and research institutions in France or abroad, or from public or private research centers.
L'archive ouverte pluridisciplinaire HAL, est destinée au dépôt et à la diffusion de documents scientifiques de niveau recherche, publiés ou non, émanant des établissements d'enseignement et de recherche français ou étrangers, des laboratoires publics ou privés. 
Gallstone disease, towards a better understanding and clinical practice

\section{Chantal Housset}

Sorbonne Universités, UPMC Univ Paris 06, INSERM, Saint-Antoine Research Center (CRSA) \& Assistance Publique-Hôpitaux de Paris, Saint-Antoine Hospital, Reference Center for Biliary Diseases, F-75012, Paris, France.

Among all digestive diseases, gallstone disease is the most common and costly one, with an estimated prevalence of $10 \%$ to $20 \%$ in the western world. Symptomatic disease is responsible for 1.4 million visits and 750,000 cholecystectomies per year in the United States. The vast majority of gallstones (more than 75\%) are of cholesterol or cholesterol-predominant type. In this issue of Current Opinion in Gastroenterology, D.M. Shabanzadeh reports on the epidemiology of gallstone disease on the basis of ultrasound screening, notably in population cohorts unaware of the presence of gallstones. These studies indicate that approximately one out of five gallstone carriers will develop symptoms, whereas the majority will remain asymptomatic. The determinants of symptomatic disease, including biliary colic and complications, consist in female gender, younger age, higher body mass index, awareness of gallstone presence, gallstone multiplicity and size above $10 \mathrm{~mm}$. Symptomatic disease exposes the patient to a high risk of symptom recurrence, and therefore justifies cholecystectomy. M. Lamberts has reviewed recent studies, which resulted in major revisions in recommendations regarding the indication and timing of cholecystectomy. Whereas a significant number of unnecessary cholecystectomies have been performed in the past, it is now recommended not to delay cholecystectomy in patients with complications such as acute cholecystitis, common bile duct stones or biliary pancreatitis, to reduce the risk of recurrent complications in these patients. Endoscopic retrograde cholangiography with sphincterotomy and stone extraction is recommended for bile duct stones. Patients with complications should undergo same-admission (laparoscopic) cholecystectomy, as opposed to delayed cholecystectomy in previous guidelines. However, some patients with uncomplicated symptomatic gallstone disease remain at high risk of persistent symptoms after cholecystectomy and should be treated conservatively. Therefore, the selection of patients for cholecystectomy still needs to be optimized, which will require the exploration of treatment algorithms in prospective clinical trials. Overweight, insulin resistance and nonalcoholic fatty liver disease (NAFLD) have been identified as potential targets, in the prevention of cholesterol gallstone disease. M Arrese et al. herein describe the frequent association and bidirectional relationship between gallstone disease and NAFLD. Insulin resistance, a well-established key 
event in the development and progression of NAFLD, was also shown to cause cholesterol gallstone formation. In addition, besides common risk factors, NAFLD has been identified as an independent risk factor of gallstone disease. Conversely gallstone disease and cholecystectomy have an impact on the development and severity of NAFLD. These observations highlight gallbladder endocrine functions and its critical role in the homeostasis of bile acids. Farnesoid X receptor (FXR), the nuclear receptor of bile acids, which regulates fat metabolism in the liver and the composition of bile, is a therapeutic target of particular interest both in NAFLD and gallstone disease. By contrast, there is evidence to indicate that the transmembrane G-protein coupled bile acid receptor, TGR5 promotes cholesterol gallstone formation. Even though cholecystectomy is currently the best option in patients with gallstone disease complications, gallbladder ablation has metabolic consequences that need to be better defined in the future. The mechanisms of cholesterol gallstone formation, reviewed by $\mathrm{P}$ Portincasa et al. primarily consist in the hypersecretion of cholesterol into bile largely through the canalicular ABCG5-ABCG8 transporter, but also involve the precipitation of cholesterol crystals, impaired gallbladder motility, increased gallbladder mucin secretion, and increased intestinal absorption of cholesterol. Genetic factors have also been elucidated, notably on the basis of mouse models, as summarized by D.Q. Wang et al. However, studies of twin pairs have suggested that genetic factors were responsible for no more than $25-30 \%$ of symptomatic gallstones. Variants of the $A B C B 4$ gene that encodes the canalicular transporter of phosphatidyl choline, can cause low phospholipid-associated cholelithiasis (LPAC), a symptomatic form of cholesterol intrahepatic cholelithiasis affecting young subjects, who benefit from long-term treatment with ursodeoxycholic acid (UDCA). Temporary UDCA treatment can also prevent gallstone formation in particular conditions, such as rapid weight loss. Recently, dysbiosis has emerged as a contributing factor correlated with an increase in the ratio of secondary over primary bile acids. Particular interest has also been raised by the pathogenic links between cholesterol gallstones and features of the metabolic syndrome. According to European guidelines, prevention of gallstone disease relies on a healthy lifestyle and food, regular physical activity and maintenance of normal body weight, which not only decrease the risk of cholesterol gallbladder stones but also the risk of symptoms due to gallstones. In summary, significant progress has occurred in the understanding of gallstone disease pathogenesis and in treatments including the indication and timing of cholecystectomy. Future studies still need to determine why gallstone disease is associated with increased overall mortality and a number of comorbid conditions including not only type 2 diabetes and ischemic heart disease, but all gastrointestinal cancers, notably proximal colon cancers. It will also be important to evaluate the impact of gallbladder ablation by itself. 